\title{
Evaluation of Tepi and Its Surrounding Coffee Collections Against Major Coffee Diseases at Gera and Tepi
}

\author{
Gabisa Gidisa*, Zenebe Wubshet, Negasa Dechasa \\ Ethiopian Institute of Agricultural Research, Jimma Agricultural Research Center, Jimma, Ethiopia
}

Email address:

gabisa1999m@gmail.com (G. Gidisa)

${ }^{*}$ Corresponding author

\section{To cite this article:}

Gabisa Gidisa, Zenebe Wubshet, Negasa Dechasa. Evaluation of Tepi and Its Surrounding Coffee Collections Against Major Coffee Diseases at Gera and Tepi. International Journal of Pharmacy and Chemistry. Vol. 7, No. 5, 2021, pp. 80-84. doi: 10.11648/j.ijpc.20210705.11

Received: August 6, 2021; Accepted: August 27, 2021; Published: September 13, 2021

\begin{abstract}
Coffee has for centuries played an important role in the Ethiopian economy and represents the main cash crop cultivated by small-scale farmers for social, economic, political and ecological sustainability. The estimated coffee production area in Ethiopia is 561,761 ha. In Ethiopia, coffee berry disease (CBD), coffee wilt disease (CWD) and coffee leaf rust (CLR) are foremost factors in reducing the quantity and quality of coffee in the country. developing disease resistant landrace coffee varieties and boost the yield with their intrinsic cup quality, a multidisciplinary research program has been designed and implemented at Jimma agricultural research center. To meet this objectives, local land race development program of Tepi 88 coffee collections were started in 2015 and 108 coffee accessions were collected and planted in 2016 at Tepi and Gera research sub centre by Jimma Agricultural Research Center. so, 88 coffee accessions were evaluated for their resistance using visual assessment, attached berry test to CBD, visual to scores CLR and laboratory inoculation test to CWD. There were significant differences among the Tepi coffee collections tested for resistance to coffee berry disease. The range was from $0 \%$ (T-83/2011) - 98\% (T-63/2011) most of Tepi coffee accessions show susceptable reaction for CBD but most of the accessions show resistance reaction at Gera. Coffee collections were also evaluated for their resistance to coffee leaf rust under field condition at Tepi research center. Highly significant difference among coffee cultivars in percent coffee leaf rust severity was observed (Table 1). Coffee leaf rust disease percent severity varied between $0.17 \%$ (T-41/2011) - 21.7\% (T-11/2011). There existed highly significant difference among cultivars both in percent wilt seedlings death and incubation period). Disease severity and incubation period on Tepi coffee collections varied between 9.33\% (T-06/2011) -97.3\% (T-21/2011) and $132-10$ days respectively. Based on over all detailed analysis of field evaluation and greenhouse test investigation for major diseases, and their Yield potentials, Nine Tepi coffee accessions were promoted to Variety verification.
\end{abstract}

Keywords: Tepi Coffee Collections, Disease Resistant, Colletotrichum Kahawae, Gibberella Xylarioides, Hemileia Vastatrix

\section{Introduction}

Coffee is the most important agricultural commodity upon which more than 50 countries including Ethiopia are dependent for their economy, especially foreign exchange earnings. Coffee has for centuries played an important role in the Ethiopian economy and represents the main cash crop cultivated by small-scale farmers for social, economic, political and ecological sustainability. The estimated coffee production area in Ethiopia is 561,761 ha [1,3]. In Ethiopia, coffee berry disease (CBD), coffee wilt disease and coffee leaf rust (CLR) are foremost factors in reducing the quantity and quality of coffee in the country. Production of land race coffee varieties adaptable to specific agro-ecological niches allows farmers to supply high quality coffee at premium prices [3]. Based on the extreme demand for coffee quality to the character of those origins (types): Harar, Yirgacheffee and Sidama brands are now internationally recognized and registered as property right to Ethiopia with their distinct character/flavour and taste [7]. In the past, the interest of coffee improvement program was to develop varieties that have a wider adaptation and distribute them to all coffee growing areas. It was however, lately realized that distribution of such limited varieties to all coffee growing 
agro-ecologies adulterate the typical quality of each specific locality or region, manifested poor adaptation and less preferred by local coffee farmers compared to their respective local cultivars [10].

Jimma Agricultural Research Center (JARC) was privileged in location specificity of Arabica coffee under defined agro-ecology, growing demand for land race coffee in the international market, and existence of genetic diversity in major coffee growing areas to gear our coffee research system towards specialty coffee variety development for each agro-ecological niche of the country [16]. The development of disease resistant land race coffee varieties addressing quality issues was started 10 years back in southeastern Ethiopia [12]. The coffee varieties were originally selected and/or collected from forest and farmers' coffee fields in semi-forest or garden production systems of Tepi area and intensively evaluated and tested for their reaction to economically important diseases in the country and assessed for yield potential and quality. In this manuscript, screening of coffee berry disease (CBD), coffee wilt disease (CWD) and coffee leaf rust (CLR) resistant coffee collections in Tepi coffee producing areas of southeastern Ethiopia, pertaining to pathological investigations are reported.

\section{Material and Methods}

\subsection{Description of the Study Area}

The laboratory, greenhouse/growth room and field studies were undertaken at Tepi, Gera and Jimma Agricultural Research Centers (JARC). Tepi Agricultural Research Center is located at $611 \mathrm{~km}$ south west of Addis Ababa at latitude of $7^{\circ} 3^{\prime} 0^{\prime \prime} \mathrm{N}$ and longitude of $35^{\circ} 18^{\prime} 0^{\prime \prime} \mathrm{E}$. and at an altitude of 1200 meters above sea level. The mean annual rainfall of the area is $1678 \mathrm{~mm}$ per annum with an average maximum and minimum air temperatures of $30^{\circ} \mathrm{C}$ and $16^{\circ} \mathrm{C}$, respectively. JARC is found in Oromia regional state in Jimma zone $360 \mathrm{Km}$ southwest of Addis Ababa. It is located around $07^{\circ} 46^{\prime} \mathrm{N}$ latitude and $36^{\circ} 47^{\prime} \mathrm{E}$ longitude coordinate and at an elevation of 1753 m.a.s.l. It represents the medium agro ecological zones which receives annual rainfall of $1572 \mathrm{~mm}$. Its mean minimum and maximum temperature is $11.6^{\circ} \mathrm{C}$ and $26.3^{\circ} \mathrm{C}$ respectively. The major soil type of the center is chromic nitosol and cambiosl of upland and fluvisol of bottom land [8].

\subsection{Treatments and Design Used}

Screening of Tepi coffee collections were conducted on 88 coffee accessions which were collected in Tepi and its surroundings coffee growing areas of south-west, Ethiopia. The laboratory, greenhouse or growth room and the field studies were conducted at Jimma Gera and Tepi Agricultural Research Center South-west, Ethiopia since the year of 2013. Coffee collections were screened for CBD and CLR at Gera CWD, at Jimma and for CLR at Tepi following the standard procedures for each disease. The treatments were outlined using Augmented Design with 10 trees per plot per accession with $2 \mathrm{~m} \times 2 \mathrm{~m}$ spacing both at Tepi and at Gera Agricultural
Research centre. The laboratory and greenhouse or growth room studies were conducted using completely randomized design (RCBD) using standard procedures [14].

\subsection{Testing for CBD Resistance}

\subsubsection{Attached Berry Test and Disease Assessment in the Field}

Besides, visual estimation of per cent CBD infection was assessed on tree base for four years, attached berry test (ABT) was used to verify their levels of resistance by inoculating good number of growing berries on three branches (top, middle and bottom canopies) of a sample coffee tree (3-5 trees/plot) with inoculum suspension of $2 \times 10^{6}$ conidia $/ \mathrm{ml}$ at field. These inoculated branches were covered with plastic sleeves with paper bags over night to favour infection. After three weeks, the number of healthy and CBD infected berries per branch were recorded and then percentage infected berries were calculated.

\subsubsection{Testing for Resistance to Coffee Wilt Disease}

Coffee accessions were tested for their reaction to coffee wilt. The seedlings (20/box) were inoculated at fully opened cotyledon stage (8-10 weeks old) with viable conidial suspension of the CWD pathogen ( $G$. xylarioides) isolate by stem nicking technique [6]. The number of wilting seedlings per box (based on external symptoms) and days to the first symptom appearance were recorded fortnightly for 6 months, and finally percentages of dead seedlings and incubation periods (day) were used for analyses. Field survival rate will be calculated by counting the number of dead trees by CWD per each plot in the interval of three months [9].

\subsubsection{Testing for Resistance to Coffee Leaf Rust}

Ten trees per accessions were considered for field CLR disease assessment using visual method [4]. Recording was started on pick time of CLR disease appearance in the field using visual assessment methods for three consecutive years. All the data's were finally transformed to angular values as necessary and analysed using online Augmented Design software [1,5].

\section{Results and Discussion}

\subsection{Testing for Coffee Berry Diseases (CBD)}

There were significant differences among the Tepi coffee collections evaluated for resistance to coffee berry disease (Colletotrichum kahawae) at Gera. In visual assessment the average severity was 98.00 percent and the range was from $0 \%$ (T-83/2011) - 98\% (T-63/2011) in 2018 cropping season because of prolonged rainfall some of the accessions show highest severity which is greater than 50 percent of coffee berry diseases.

From these T-63/2011, T-30/2011, T-22/2011, T58/2011T-56/2011, T-16/2011, T-28/2011, T-32/2011, and T07/2011 which exhibited 98, 96, 95, 95, 94, 94, 85, 85, and 77 respectively.

Some of the accessions showed significantly lower disease severity $(<5 \%)$ namely, T-83/2011, T-81/2011, T-75/2011, T-76/2011, T-68/2011, T-70/2011, T-79/2011, T-42/2011, T- 
85/2011, T-69/2011, T-02/2011T-48/2011, and T-87/2011, indicating higher CBD resistance (Table 1).

Table 1. The mean values of Tepi and its Surroundings Coffee Collections for CBD Visual and attached berry test reaction at Gera.

\begin{tabular}{llllll}
\hline Gera & Mean \% CBD & & & & \\
\hline Acc. no. & $\mathbf{2 0 1 6}$ & $\mathbf{2 0 1 7}$ & $\mathbf{2 0 1 8}$ & 3 Years mean & \%ABT \\
\hline T-87/2011 & 0.04 & 1.00 & 0.00 & 0.35 & 1.15 \\
T-46/2011 & 0.01 & 0.05 & 0.02 & 0.03 & 2.54 \\
T-79/2011 & 0.02 & 1.06 & 0.02 & 0.37 & 2.44 \\
T-42/2011 & 0.02 & 0.10 & 0.00 & 0.04 & 2.77 \\
T-76/2011 & 1.78 & 0.20 & 0.74 & 0.32 \\
T-70/2011 & 0.26 & 0.03 & 0.00 & 0.01 & 2.03 \\
T-68/2011 & 0.01 & 0.20 & 0.02 & 0.07 & 0.32 \\
T-75/2011 & 0.00 & 0.03 & 0.00 & 0.02 & 1.26 \\
T-81/2011 & 0.01 & 0.01 & 0.00 & 0.01 & 0.98 \\
7514 & 0.01 & 0.35 & 0.00 & 0.12 & 0.82 \\
741 & 0.00 & 1.05 & 2.20 & 0.75 & 1.59 \\
7416 & 0.01 & 30.96 & 0.00 & 0.35 & 1.2 \\
mean & 0.01 & 0.21 & 8.4 & 31 \\
LSD & 0.03 & ns & 2.04 & \\
CV (\%) & 1.3 & 12 & 4.1 & \\
\hline
\end{tabular}

$\mathrm{ABT}=$ attached berry test, $\mathrm{CBD}=$ coffee berry disease.

\subsection{Testing for Coffee Wilt Diseases (CWD)}

There existed highly significant difference among Tepi coffee collections both in percent wilt seedlings and incubation period (Table 2). Disease severity and incubation period on Tepi coffee collections varied between 9.33\% (T-06/2011) 97.3\% (T-21/2011) and $132-10$ days respectively. Accessions T-72/2011, T-37/2011, T-62/2011, T-32/2011, T-81/2011, T77/2011, T-43/2011, T-67/2011, T-26/2011, T-85/2011, T48/2011, and T-55/2011 resulted highest percentage (> 90\%) seedling death i.e 97.33, 97.28, 95.94, 93.28, 92.98, 92.08, $91.89,91.7$ and 90.32 with short incubation period of 100, 123,
$90.6,90.7,104.6,70,108.3,100,100$, and 90.7 respectively (Table 2). Coffee accessions T-06/2011, T-07/2011 andT$11 / 2011$ shows resistant reaction with severity percent of 9.33 , 17.8, 21.8 and incubation period of $132.65,151.3$, and 118.6 days. However, coffee accessions T-05/2011, T-36/2011 and T-34/2011 shows moderately susceptible with severity of 25.2 , 25.5, and 25.7\%and incubation period of 114, 76.7, and 128 days (Table 2). No Coffee cultivar shows highly resistance reaction as compared to the checks 279 (6.7) and 370 (26.1) seedling death and incubation period 128 and 156 respectively [13] (Table 2).

Table 2. Reaction of Tepi coffee collections for Coffee leaf rust (3 yrs) and coffee wilt diseases at Tepi and Jimma.

\begin{tabular}{|c|c|c|c|c|c|c|c|}
\hline Ace. no & CLR\% & CWD\% & IP\% & Ace. no & CLR\% & CWD\% & IP\% \\
\hline T-01/2011 & 5.33 & 56.72 & 118 & T-28/2011 & 1.83 & 64.00 & 109.3 \\
\hline $\mathrm{T}-02 / 2011$ & 10.83 & 48.34 & 118 & T-29/2011 & 6.83 & 81.33 & 95.3 \\
\hline $\mathrm{T}-03 / 2011$ & 8.5 & 83.89 & 95.3 & T-30/2011 & 15.83 & 52.00 & 118. \\
\hline T-04/2011 & 7.67 & 68.83 & 95.3 & $\mathrm{~T}-31 / 2011$ & 7.5 & 83.88 & 76.0 \\
\hline $\mathrm{T}-05 / 2011$ & 6.00 & 27.17 & 114 & $\mathrm{~T}-32 / 2011$ & 13.3 & 93.17 & 90.7 \\
\hline T-06/2011 & 6.00 & 9.33 & 132.6 & $\mathrm{~T}-33 / 2011$ & 1.17 & 44.83 & 100 \\
\hline T-07/2011 & 6.67 & 17.78 & 151.3 & T-34/2011 & 3.67 & 25.72 & 128 \\
\hline T-09/2011 & 6.00 & 46.83 & 104.7 & $\mathrm{~T}-36 / 2011$ & 6 & 27.52 & 76.7 \\
\hline T-10/2011 & 1.17 & 48.83 & 118.6 & $\mathrm{~T}-37 / 2011$ & 3.67 & 97.28 & 123 \\
\hline $\mathrm{T}-11 / 2011$ & 21.67 & 21.80 & 118.6 & $\mathrm{~T}-38 / 2011$ & 0.67 & 76.21 & 123 \\
\hline $\mathrm{T}-12 / 2011$ & 10.0 & 38.22 & 114 & T-39/2011 & 0.33 & 71.30 & 10 \\
\hline T-13/2011 & 8.33 & 51.99 & 128 & $\mathrm{~T}-40 / 2011$ & 1.17 & 85.11 & 137.3 \\
\hline T-14/2011 & 0.67 & 71.92 & 104.6 & $\mathrm{~T}-41 / 2011$ & 0.17 & 87.38 & 90.7 \\
\hline $\mathrm{T}-15 / 2011$ & 6.00 & 37.55 & 137.3 & $\mathrm{~T}-42 / 2011$ & 3.83 & 74.61 & 114 \\
\hline $\mathrm{T}-17 / 2011$ & 1.17 & 57.54 & 114.0 & $\mathrm{~T}-44 / 2011$ & 1.17 & 87.39 & 95.3 \\
\hline T-18/2011 & 0.33 & 76.89 & 132.6 & $\mathrm{~T}-45 / 2011$ & 5.33 & 81.62 & 90.6 \\
\hline T-19/2011 & 3.33 & 75.56 & 118.6 & $\mathrm{~T}-46 / 2011$ & 3 & 73.00 & 104 \\
\hline T-20/2011 & 3.00 & 74.67 & 109.3 & $\mathrm{~T}-47 / 2011$ & 2.17 & 79.22 & 95.3 \\
\hline T-21/2011 & 0.83 & 95.94 & 104.6 & $\mathrm{~T}-48 / 2011$ & 4.5 & 90.56 & 90.6 \\
\hline T-22/2011 & 1.17 & 42.79 & 109.3 & T-49/2011 & 1.17 & 40.15 & 76.6 \\
\hline T-23/2011 & 5.17 & 95.94 & 70 & $\mathrm{~T}-50 / 2011$ & 1.33 & 85.43 & 81.3 \\
\hline T-24/2011 & 0.33 & 59.42 & 128.0 & $\mathrm{~T}-52 / 2011$ & 0.83 & 64.33 & 90.6 \\
\hline T-25/2011 & 2.00 & 80.00 & 90.6 & $\mathrm{~T}-53 / 2011$ & 0.67 & 84.42 & 104 \\
\hline T-26/2011 & 1.83 & 91.89 & 86 & $\mathrm{~T}-53 / 2011$ & 0.33 & 79.39 & 109 \\
\hline T-27/2011 & 7.67 & 77.10 & 100 & T-54/2011 & 0.33 & 86.67 & 86 \\
\hline
\end{tabular}


Table 2. Continued.

\begin{tabular}{|c|c|c|c|c|c|c|c|}
\hline Ace. no & CLR\% & CWD\% & IP\% & Ace. no & CLR\% & CWD\% & IP\% \\
\hline $\mathrm{T}-55 / 20111$ & 1.17 & 90.32 & 100 & $\mathrm{~T}-82 / 2011$ & 7.5 & 76.61 & 86.00 \\
\hline $\mathrm{T}-56 / 2011$ & 6.17 & 72.71 & 95.3 & T-83/2011 & 5.83 & 84.00 & 90.67 \\
\hline T-57/2011 & 0.17 & 71.15 & 90.6 & T-84/2011 & 1.83 & 86.67 & 95.33 \\
\hline $\mathrm{T}-58 / 2011$ & 2.83 & 74.70 & 104.6 & $\mathrm{~T}-85 / 2011$ & 11.67 & 91.67 & 95.33 \\
\hline T-59/2011 & 2.83 & 73.72 & 90.6 & T-86/2011 & 15 & 64.00 & 86.00 \\
\hline T-60/2011 & 0.5 & 83.75 & 86.0 & $\mathrm{~T}-87 / 2011$ & 2.17 & 84.00 & 100 \\
\hline T-61/2011 & 3 & 86.20 & 95.3 & T-88/2011 & 2 & 82.41 & 100 \\
\hline T-63/2011 & 1.33 & 80.00 & 100 & $\mathrm{~J}-19$ & 12.5 & 78.09 & 100 \\
\hline T-64/2011 & 0.67 & 86.56 & 90.6 & F-59 & 3.54 & 79.39 & 90.7 \\
\hline T-66/2011 & 0.67 & 87.88 & 100 & 7454 & 6.5 & 74.20 & 81.3 \\
\hline T-67/2011 & 2.67 & 92.00 & 104.6 & 7440 & 7.08 & 78.67 & 109.3 \\
\hline T-68/2011 & 10 & 88.00 & 90.7 & 279 & - & 6.67 & 128 \\
\hline T-69/2011 & 10 & 85.39 & 86.0 & 370 & - & 26.09 & 156 \\
\hline $\mathrm{T}-70 / 2011$ & 2.17 & 81.06 & 100 & mean & 4.3 & 71.00 & \\
\hline $\mathrm{T}-73 / 2011$ & 2.17 & 66.39 & 100 & & & & \\
\hline T-74/2011 & 2.17 & 67.22 & 86 & & & & \\
\hline T-75/2011 & 2.17 & 87.38 & 95.3 & & & & \\
\hline T-76/2011 & 1.5 & 89.17 & 90.7 & & & & \\
\hline T-77/2011 & 0.4 & 93.28 & 100 & & & & \\
\hline T-78/2011 & 3 & 76.00 & 86 & & & & \\
\hline T-79/2011 & 0.33 & 89.08 & 90.7 & & & & \\
\hline T-80/2011 & 1.17 & 76.72 & 100 & & & & \\
\hline T-81/2011 & 0.33 & 93.28 & 100 & & & & \\
\hline T-55/2011 & 0.33 & 56.46 & 100 & & & & \\
\hline
\end{tabular}

\subsection{Testing for Coffee Leaf Rust (CLR)}

Three years Tepi coffee collections were evaluated for their resistance to coffee leaf rust under field condition at Tepi Research Center. Highly significant difference among coffee cultivars in percent coffee leaf rust severity was observed (Table 1). Coffee leaf rust disease severity varied between $0.17 \%$ (T-41/2011) - 21.7\% (T-11/2011).

Accessions T-41/2011, T-57/2011, T-39/2011, T-33/2011, T-54/2011, T-18/2011, T-16/2011, T-24/2011, T-81/2011, T55/2011, T-77/2011, T-64/2011, T-66/2011, T-38/2011, T14/2011, T-21/2011 and T-52/2011 resulted low percentage $(<1 \%)$ CLR severity $0.17,0.17,0.33,0.33,0.33,0.33,0.33$, $0.33,0.4,0.6,0.67,0.83$ and $0.83 \%$ respectively showing highly resistance reaction. Coffee cultivar T-40/2011, T44/2011, T-63/2011, T-26/2011, T-28/2011, T-25/2011, T70/2011, T-73/2011, T-67/2011, T-62/2011, 58/2011, and T$59 / 2011$, shows resistant reaction $(<5 \%)$ i.e., $1.2,1.2,1.3$, $1.7,1.8,2.00,2.2,2.2,2.7,2.8,2.8$, and $3.00 \%$, coffee leaf rust severity (Table 2). Coffee cultivars T-02/2011, T85/2011, Gesha, T-32/2011, T-30/2011, and T-11/2011 exhibited moderately susceptible reaction $(>10 \%)$ with Coffee Leaf Rust severity value of $10.8,11.7,12.4,13.3$, 15.8 , and $21.7 \%$ respectively (Table 2 ).

\section{Summary and Conclusion}

Ethiopia is the centre of origin and diversity of Arabica coffee. The country is ecologically very diverse and coffees grown under these environments are different in quality, disease resistance, yield potential and many other traits. A new breeding strategy, known as 'Local Coffee Landrace Variety Development Program', was designed with main objective to develop high yielding and disease resistant cultivars with good quality for the major coffee growing areas of Ethiopia [2]. Local land race variety development program of Tepi coffee collections were started in 2011 and 88 coffee accessions were collected from shako zone of Tepi and its surrounding districts in 2011 and planted in 2008 at Tepi research centre and in 2008 at Gera Research sub center. Accordingly, 88 coffee accessions were evaluated for their resistance to Coffee Berry Disease Coffee wilt disease and Coffee leaf Rust using visual assessment and laboratory inoculation method [11].

There were significant differences among the Tepi coffee collections evaluated for resistance to coffee berry disease (Colletotrichum kahawae) at Gera. In visual assessment the average severity was 15.74 percent and the rage was from $0 \%$ (T-83/2011) - 98\% (T-63/2011) some of the accessions show highest severity which is greater than 50 percent of coffee berry diseases. Since Tepi has divers agro-ecologies especially seven coffee collections which were CBD resistance are suitable at higher altitude [15]. Three years Tepi coffee collections were evaluated for their resistance reaction to coffee leaf rust under field condition at Tepi research center. There existed highly significant difference among coffee cultivars in percent coffee leaf rust severity (Table 2). Coffee leaf rust disease severity varied between $0.17 \%$ (T-41/2011) - 21.7\% (T-11/2011). Highly significant difference among Tepi coffee accesions both in percent wilt seedlings death and incubation period (G. xylarioides) (Table 2). Disease severity and incubation period on Tepi coffee 
collections varied between 9.33\% (T-06/2011) -97.3\% (T21/2011) and 132-10 days respectively. So based on over all detailed analysis of field evaluation and greenhouse investigation 17 of Tepi coffee accessions are promoted for variety verification pretending that they have other required traits like yield and good cup quality.

\section{Acknowledgements}

The Authors would like to acknowledge Ethiopian Institute of Agricultural Research, Jimma Agricultural Research Center for providing laboratory and greenhouse facilities. Moreover, authors acknowledge all staffs of plant pathology research laboratory. We thank Mr. Sisay Tesfaye, Mr. Mamo Abye and Mr. Wakuma from Tepi Research center for their technical support throughout the experiment.

\section{References}

[1] Arega Z., Demelash T., Chala J., Sisay T., Mesfin S. and Girma A. 2008. Success Stories in Managing Coffee Berry Disease in Ethiopia. Pp 239-249. In: Coffee Diversity and Knowledge.

[2] Bayetta B., Tesfaye S., Endale T., and Taye, K. (Eds.). Proceedings of a National Workshop Four Decades of Coffee Research and Development in Ethiopia, 14-17 August 2007, Addis Ababa, Ethiopia.

[3] Eshetu Derso. 1997. Coffee diseases and their significance in Ethiopia. ASIC 17 (I): 723-726.

[4] Eskes, A. B. and M. Toma-Braghini, 1981. Assessment methods for resistance to coffee leaf rust Hemileiavastatrix. FAO Plant Protection Bulletin, 29: 56-66.

[5] Girma Adugna. 2004. Diversity in pathogenicity and genetics of Gibberellaxyilarioides (Fusarium xylarioides) population and resistance of coffee spp. in Ethiopia. Doctoral Dissertation. Hoen Landwirtschaftlichen Fakult'a' der Rheinischen Friedrich-Wilhelms-Universit'a't zu Bonn. 81 pp.

[6] Girma Adugna, Mengistu Hulluka and Hindorf, H. 2001. Incidence of tracheomycosis, Gibberella xyilarioides (Fusarium xylarioides), on Arabica coffee in Ethiopia.
[7] IPO. 2008. Intellectual Property Office Report.

[8] JARC, 2006. Jimma Agricultural research center annual progress report. 2005, Jimma, Ethiopia.

[9] Phirii N., Baker p., Ruther ford M., Flood J., Musoli P., Mmugi K., Kiambo D., Aduna G., Hakiza G., Pinard F., Odour G. 2010. The regional coffee wilt program Where do we go. In: Proceedings of $23^{\text {rd }}$ International Scientific Colloquium on Coffee (ASIC) $3^{\text {rd }}-8^{\text {th }}$ October, 2010. Bali, Indonesia, pp. 537-548.

[10] Taye K., Tesfaye S. and Alemseged Y. 2004. Adaptation of Arabica coffee landraces along topographic gradients in southern Ethiopia. In: Proceedings of the $20^{\text {th }}$ International Conference on Coffee Science (ASIC), 11-15 October 2004, Bangalore, India, pp 1046-1052.

[11] Tefestewold B. 1995. Studies on Collototrichum population of Coffea arabica L. In Ethiopia and evaluation of reactions of coffee germplasm. Ph.D Diss., University of Bonn, Germany. $231 \mathrm{pp}$.

[12] Van der Graff, N, A. 1981. Selection of Arabica coffee types resistant to coffee berry disease in Ethiopia. Mededelingen Londbovwhogeschola, Wagningen, pp 110 pp.

[13] Demelash T, and Kifle B, 2015. Evaluation of released arabica coffee varieties (coffea arabica 1) for major coffee diseases with especial emphasis to coffee wilt disease (Gibberella xylarioides) at jimma, Ethiopia journal of Biology and healthcare.

[14] Bayetta Belachew, Behailu Atero and Fekadu Tefera (2000), Breeding for the resistance to coffee berry disease in arabica coffee: progress since 1973. In: In: proceedings of the workshop on control of coffee berry Disease (CBD) in Ethiopia, pp. 85-97. 13-15 August 1999, Addis Ababa, Ethiopia.

[15] CABI. (2003), Surveys to assess the extent of coffee wilt disease in East and Central Africa. Final technical report. CABI Regional Center, Nairobi, Kenya. 49 pp.

[16] CSA (Central Statistical Authority). (2010), Agricultural sample survey. Report on landutilization, Federal Democratic Republic of Ethiopia, Addis Ababa, Ethiopia. 